\title{
The 'Most Important and Fundamental' Distinction in Logic
}

\section{G. C. Godvu University of Richmond}

\begin{abstract}
In this paper I argue that the debate over the purported distinction between deductive and inductive arguments can be bypassed because making the distinction is unnecessary for successfully evaluating arguments. I provide a foundation for doing logic that makes no appeal to the distinction and still performs all the relevant tasks required of an analysis of arguments. I also reply to objections to the view that we can dispense with the distinction. Finally, I conclude that the distinction between inductive and deductive arguments is not one of the most important and fundamental ideas in logic, but rather is unnecessary.
\end{abstract}

Résumé: Je défends l'idée que le débat sur la distinction entre les arguments déductifs et inductifs peut être abandonné parce que cette distinction n'est pas nécessaire pour bien évaluer un argument. Je décris un fondement pour l'évaluation des arguments qui ne fait pas appel à cette distinction, mais qui tout de même tient compte de toutes les tâches pertinentes pour une évaluation bien réussie. Je réponds à des objections contre l'idée qu'on peut se dispenser de l'usage de cette distinction. Je conclus que la distinction entre des arguments inductifs et déductifs n'est pas une des idées les plus importantes et fondamentales de la logique, et qu'elle n'est même pas nécessaire.

Keywords: Argument, deductive, inductive, adequacy, reasoning

Nicholas Rescher, in An Introduction to Logic, writes, '[t]he distinction between deductive and inductive arguments is one of the most important and fundamental ideas in logic." The distinction is not limited to logic: it shows up in rhetoric, legal reasoning, the philosophy of science, and many discussions concerning argumentation in general. The distinction is pervasive, but not without controversy. Assuming Rescher is correct, one wants to know exactly what the fundamental and important distinction is and here tremendous disagreement and conflict exists. I hope to bypass the disagreement about what exactly the distinction is by attacking the prevailing sentiment embodied in Rescher's statement. I shall argue that the distinction between deductive and inductive arguments, if there even is one, is not important or fundamental at all. Trying to distinguish deductive and inductive arguments is completely unnecessary.

In Section I, I shall briefly outline the traditional structure of the debate concerning making the distinction and justify my undercutting of the traditional structure. In Section II, I shall provide a foundation for doing logic that makes no 
appeal to the distinction and is able to perform all the relevant tasks we want of an analysis of arguments. In Section III, I shall consider actual and possible objections to the view that we can dispense with the distinction. Finally, I shall conclude that the distinction between inductive and deductive arguments is not one of the most important and fundamental ideas in logic, but rather is irrelevant and unnecessary.

I

Despite the almost universal agreement with Rescher's sentiment, there is little agreement on the exact nature of the alleged distinction between deductive and inductive arguments. Consider, for example, the following quotations from recent logic textbooks:

A deductive argument is one whose conclusion is claimed to follow from its premises with absolute necessity, ... in sharp contrast, an inductive argument is one whose conclusion is claimed to follow from its premises only with probability, this probability being a matter of degree and dependent upon what else may be the case. ${ }^{2}$

In a deductive argument, the conclusion is contained implicitly within the premises; the argument merely draws it out, making it explicit. ... [In an inductive argumęnt the] conclusion is certainly supported by the premises, but it is not contained in them in the same way as in deduction. ${ }^{3}$

There are inductive families - families of arguments appropriately evaluated by inductive means. Likewise there are deductive families. Recognizing that an argument belongs to one of those families allows us to classify it as inductive or deductive. ${ }^{4}$

Debate concerning how to draw the distinction between deductive and inductive arguments has traditionally been structured as follows: Firstly, demonstrate why previous attempts to make the distinction are inadequate and then secondly, either (i) merely suggest how a viable distinction might be formulated, or (ii) actually provide and defend a new version of the distinction, or (iii) argue that some distinction with more than just the two traditional categories is required or (iv) abandon the distinction altogether.

Given that, to date, I have found no fewer than 20 different versions of the distinction, to do the first step justice, I would need to argue against all these distinctions and that would be a long and tedious task. ${ }^{5}$ Instead, I shall undercut the entire traditional debate by arguing that even if there were an agreed upon viable distinction, it wouldn't do any work that couldn't get done in a more elegant way. Put another way-we can do our job as logicians just as well, if not better, without making a purported distinction between deductive and inductive arguments. If so, the burden of proof should be on the advocates of the distinction to prove that the distinction is necessary or, at least, that making the distinction is more useful than not making it. Also, if I can show that we do not need a distinction between deductive and inductive arguments, then we need not bother with 
either step in the traditional debate. I turn now to my own account and my defense of the claim that distinguishing deductive from inductive arguments is unnecessary.

\section{A. Arguments}

Regardless of whether one thinks arguments can be profitably subdivided into deductive and inductive classes, we first need to know what an argument is. I define 'argument' as follows:

(i) An argument is a group of statements, one of which is designated the conclusion.

For example, from the text: 'All is well in Denmark and George is in Denmark, so George is well' we can extract the statements: 'All is well in Denmark,' 'George is in Denmark,' and 'George is well.' (Exactly how one breaks compound sentences into the relevant statements is not my concern here.) The illative 'so' in the original text designates 'George is well' as the conclusion, so the text is an argument, which we can also represent as follows:

All is well in Denmark.

George is in Denmark.

George is well.

Many might object that the definition omits the essential feature that makes a group of statements an argument-namely that there is some connection between the conclusion and the remaining statements, the premises. The exact nature of the alleged connection is certainly not agreed upon, but, for the most part, 'argument' has been defined such that to be an argument the conclusion must be claimed to follow from ${ }^{6}$, or affirmed on the basis of the premises or the premises must be attributed favorable relevance to ${ }^{8}$, or be taken to support ${ }^{9}$ the conclusion, etc.

Is some connection between conclusion and premises truly an essential part of being an argument? Not everyone defines 'argument' such that it is. ${ }^{10}$ Also, suppose someone writes an argument generator program that works by having the computer randomly generate sentences of English and then print them out in groups of three, with the word 'Conclusion' before the last. Some outputs of such a program might be:

The sky is purple.

All humans have a nose.

Conclusion: All is well in Denmark.
George is human.

All humans have a nose.

Conclusion: George has a nose.

Neither the programmer nor the computer claims that the conclusion follows from or is supported by the premises, yet to deny that the computer outputs arguments is to repudiate the programmer's intentions, the quite explicit form of the computer's output, and our ability to coherently ask whether the outputs constitute good or bad arguments. 
Perhaps some will claim that the computer's outputs count as arguments because even though there is no explicit claim, there is the implicit claim or implication that the conclusion is supposed to follow from the premises. What could be the source of this implication? The only candidate is the designation of the last sentence as the conclusion. Nothing else is present to distinguish the computer's outputs from mere lists of statements. If conclusions are just those statements arrived at on the basis of others, then by designating one statement as the conclusion we imply it follows from, or at least is supposed to follow from, the others. But if the mere designation of one statement as the conclusion is sufficient to imply it is supposed to follow from the others, then the given definition of 'argument' does not omit the alleged essential feature of arguments.

The only other option is to deny that the computers' outputs are arguments on the grounds that the mere designation of one of a set of statements as the conclusion is not sufficient to imply that it is supposed to follow from the others. But then countless other texts naturally construed as arguments must also be rejected. For example, 'Socrates is a man, so Socrates is mortal' or 'Socrates is mortal, thus Socrates is a living being' would have to be rejected as arguments because there is nothing but the conclusion indicators 'so' and 'thus' to imply any connection between conclusion and premise. If 'so' and 'thus' alone are insufficient and to be an argument requires some connection between conclusion and premises, then, contra the natural interpretation, the Socrates texts are not really arguments. Hence, if the mere designation of a conclusion is not sufficient to imply the conclusion is supposed to follow from the remaining statements, then a connection between premises and conclusion is not an essential part of being an argument.

To sum up: either the mere designation of one statement as the conclusion implies a connection or it does not. If it does, then the given definition implies a connection and so should satisfy those who claim that a connection between conclusion and premises is an essential part of being an argument. If it does not, then a connection between premises and conclusion is not an essential part of being an argument, for otherwise too many texts that express arguments would be ruled non-arguments.

One final comment about the definition of argument. The most common means of designating the conclusion is via an illative such as 'so,' 'hence,' or 'thus,' etc. However, while examining and enumerating the various ways of designating conclusions is not my concern here, 1 will point out that the designation of the conclusion need not be explicit and in some cases the conclusion itself can be left implied. For example, consider the following paragraph from Descartes' Meditations on First Philosophy:

Surely whatever I had admitted until now as most true I received either from the senses or through the senses. However, I have noticed that the senses are sometimes deceptive; and it is a mark of prudence never to place our complete trust in those who have deceived us even once." 
Given Descartes' already stated goal of casting all his former opinions into doubt by attacking the principles upon which those opinions are founded, the following argument can be extracted from the text:

The senses are sometimes deceptive.

We should not place our complete trust in those who have deceived us even once.

We should not place our complete trust in the senses.

Whatever I had admitted until now as most true I received either from the senses or through the senses.

All I had admitted until now as most true should not be completely trusted.

Descartes states neither conclusion explicitly and so designates neither conclusion explicitly, yet clearly Descartes is offering an argument in the quoted passage.

\section{B. Adequate Arguments}

Suppose wè have an argument, a group of statements, one of which is designated the conclusion. Presumably, our primary concern is to know whether the argument is good or not. At the very least, for an argument to be good the premises must provide adequate support for the conclusion. What exactly is adequate support? I define 'adequate support', as follows:

(ii) The premises adequately support the conclusion in a context, $\mathrm{T}$, iff the strength by which the premises support the conclusion in $\mathrm{T}$ is at least as'great as the strength required by $T$.

The context of an argument will be the relevant features of either the actual situation in which the argument is used or the hypothetical situation in which we are imagining the argument being used. Which features are relevant? At the very least, those features that have a bearing on the evaluation of the argument. In regards to adequate support the relevant facts will be those facts that are being held constant for the determination of how probable the conclusion is, given the premises and those facts that bear on how much support the conclusion requires. In order to further clarify adequate support, I provide the following examples.

Example I: Consider the following argument:

(1) All examined emeralds up to now are green, so the next emerald examined will be green.

If the premise alone is the only fact held constant through all logically possible situations, then there is a certain degree of support, call it $n$, that the premise conveys upon the conclusion. If, however, we also hold constant that the laws of the universe do not change immediately after 'now' we presumably get a support value greater than $n$. If, on the other hand, we hold constant that a process for artificially producing red emeralds has just been developed, we might get a support value less than $n$. So depending upon which, if any, additional facts are held constant, the premise will provide varying degrees of support to the conclusion. The 
facts that, in addition to the premises, are held constant will be part of the context of the argument.

Example II: Suppose the prosecution in a criminal trial has a body of evidence, $\mathrm{E}$, that makes it probable beyond a reasonable doubt that the defendant committed the crime. So the prosecution argues,

(2) E, so the defendant committed the crime.

Suppose also that the defence is unable to provide any further relevant evidence. Ideally the jury convicts. Now suppose, however, that the defense introduces a piece of evidence not included in E; viz, that the gloves found at the crime scene do not fit the defendant. Suppose further that given that the gloves do not fit, E, while still making it highly likely, no longer makes it probable beyond a reasonable doubt that the defendant committed the crime. Ideally, the defendant is found not guilty. Finally, suppose that the exact same argument, ' $E$, so the defendant committed the crime' is made at a civil trial. The defense introduces the evidence that the gloves do not fit, and yet given the preponderance of the evidence-standard in civil trials, the jury still convicts.

The prosecution's argument, made in a context involving no further evidence and a support requirement of beyond reasonable doubt succeeds, but made in a context involving the fact that the gloves do not fit fails to meet the support requirement. Lower the degree of support required for the conclusion and the argument once again succeeds. Hence, facts determining what degree of support is required are part of the context.

As the examples show, adequate support depends upon the context of the argument. When Descartes seeks certainty, nothing less than the premises making the conclusion absolutely certain will do. When a medical researcher argues that a new drug is safe, we demand an extremely high degree of confidence. When we engage in our everyday lives, a reasonable level of assurance will do. When a defense lawyer attempts to acquit his or her client, reasonable doubt of the accused's guilt will do.

Given the definition of adequate support we can define arguments as adequate as follows:

(iii) An argument is adequate in a context $\mathrm{T}$ iff the premises adequately support the conclusion in $\mathrm{T}$.

In addition, I shall define arguments as good as follows:

(iv) An argument is good in a context $\mathrm{T}$ iff all the premises are true and the argument is adequate. ${ }^{12}$

Definitions (i)-(iv) hold for all arguments. To determine the goodness of an argument, any argument, we need to know whether the premises are all true and whether the argument is adequate. To determine whether the argument is adequate we need to know the actual support the premises convey on the conclusion and the support required by the context. No distinction between inductive and deductive arguments is needed. 
However, just to reassure you that I do not diverge from actual logic practice too much, let me mention a special case of adequacy, viz. validity. Since necessity is the highest degree of strength, any argument in which the conclusion follows from the premises by necessity is one in which the actual strength of the premise/ conclusion relationship is greater than the required strength. Hence, any argument in which the premises necessitate the conclusion is adequate. Traditionally, such arguments are said to be valid, which I define as follows:

(v) An argument is valid iff it is impossible for all the premises to be true and the conclusion false.

Regardless of the contextually required strength, valid arguments are such that the premises adequately support the conclusion. Since determining validity is straightforward, and, unlike any other case of adequacy, context independent, validity is, not surprisingly, the most studied adequacy condition and also the most amenable to formal investigation.

But what of cases in which the argument is not valid, but some strength less than absolute necessity is sufficient? Without doubt, evaluation becomes a much more difficult task and disagreement concerning evaluation becomes much more pronounced, especially in an endeavour in which one is trying to convince others of some proposition based on other propositions. Such disagreements might help explain why determining adequacy in all but the limiting case of validity is a much more nebulous and subjective affair. ${ }^{13}$

The methods and problems of actually determining with a sufficient degree of accuracy both the actual degree of support and the required degree of support are well beyond the scope of this paper. Regardless, I can at least suggest the following. Firstly, the extensive work in probability theory will be relevant to determining the actual degree of support. Secondly, ideally, the required degree of strength will be determined by an interplay of (i) the goal of accepting truths and rejecting falsehoods and (ii) the cost of rejecting what turn out to be truths and (iii) the cost of accepting what turn out to be falsehoods. We reject Descartes' demands for absolute certainty concerning matters of fact, for it accepts so few, if any, matters of fact as true that we could not function in the world. We accept pure mathematics' demands for absolute certainty, because there is little, if any, cost to rejecting what turn out to be truths. ${ }^{14}$ Since the consequences of serious side effects in a drug for treating headaches are more severe than the consequences of serious side effects in a drug given to otherwise terminal patients, the degree of confidence required for the claim that a drug is safe can vary. In legal situations, we try to balance the consequences of failing to protect society and of punishing the innocent to arrive at those levels of support required for conviction. In general, one's willingness to adopt or act upon a proposition is, ideally, at least partially determined by the consequences of accepting the proposition and the proposition turning out to be false. 
Do we need to make the distinction between deductive and inductive arguments in order to determine whether or not an argument is adequate or not? No. All that is required is that we first determine with a sufficient degree of precision the actual strength of the relationship between premises and conclusion. If the strength is necessity then the argument is valid and thus adequate. If the strength is not necessity, then we need to determine what strength is required with enough specificity to determine whether the actual strength is at least as great as the required strength. If the actual strength is at least as great as the required strength, then the argument is adequate; otherwise it is not.

So it is adequacy and the truth of premises which are relevant for evaluating arguments, not determining whether an argument is deductive or inductive. Any argument can be properly evaluated without ever determining what kind of argument is being presented. ${ }^{15}$

III

I now turn to five objections to my claim that making the distinction between inductive and deductive arguments is unnecessary.

\section{Objection 1: Actual Practice}

Samuel Fohr, in response to a proposal advanced by David Hitchcock, writes:

In wishing to discard the deductive-inductive distinction Hitchcock is running up against the actual practice of philosophers doing logic. When faced with judging the worth of an argument philosophers will commonly decide how it is to be analyzed and only then examine it. In other words, antecedently to judging it they will decide how it is to be judged .... Are philosophers deluded into thinking that arguments fall into two categories? Have they been going about things in the wrong way for these many years? ${ }^{16}$

Trudy Govier shares Fohr's concerns when she writes, 'one naturally hesitates to think that a distinction which has been around for so long, and around which so much teaching of logic has been organized, could simply be ill-founded. ${ }^{17}$

Reply: I am not convinced that Fohr is in fact right about the actual practice of argument evaluators, i.e. that prior to judging arguments we determine how it is to be judged. Regardless, suppose Fohr is correct about actual practice. Are philosophers, therefore, by my account deluded? Have they been teaching logic organized around an ill-founded distinction? The answer to both questions is quite possibly 'yes.' Logicians did logic à la Aristotle for centuries. One need only look at the contortions 19 th century logicians went through, trying to force arguments into the categorical forms to realize that Aristotle's system was grossly insufficient for the task. Despite thousands of years of tradition, Aristotle's categorical logic is no longer a primary logical system. The mere fact that a practice has been engaged in for a long time in no way indicates that the practice is necessary or useful or even adequate for achieving the goals for which the practice was implemented. 
I admit that just saying that perhaps traditional logic practice is fundamentally flawed might strike many as unsatisfactory. After all, presumably present logicians are not blindly following in the footsteps of those who came before. Surely, some might object, there has to be something to the inductive/deductive distinction such that it has occupied such a central place in the teaching and study of logic.

I grant that perhaps there is something to the distinction, for I am only claiming that there is no need to type arguments as either deductive or inductive and there are several distinctions one could make that are (a) consistent with my framework and (b) could capture what logicians are trying to articulate when they appeal to induction vs. deduction. For example, some logicians distinguish deductive reasoning from inductive reasoning or deductive logic from inductive logic without distinguishing deductive arguments from inductive arguments. ${ }^{18}$

I am perfectly willing to distinguish deductive/inductive reasonings or logics. Reasonings, we can hold, just are mental acts or processes - happenings inside our heads which are not accessible to logicians for general inspection. ${ }^{19}$ Reasonings can be split into at least two kinds-deductions and inductions. To deduce $\mathrm{A}$ from $B$ is to come to believe that $A$ must be true on the basis of $B$. To induce $A$ from $B$ is to come to believe that $A$ is reasonable, but not necessary, on the basis of $B$. The distinction between the two types of reasonings, i.e. deductions and inductions, is one of what we believe the relationship between conclusion and premises to be.

But what we believe the relationship to be is irrelevant to the goodness or badness of arguments - sets of statements, one of which is designated the conclusion. One can believe that the fact we are all mortal merely makes it probable we will all die, and can believe that the fact that grass is green makes it certain that Jupiter is the mightiest of all the gods, and be wrong in both instances. To determine the adequacy of arguments we need to discover what the actual relationship is and what the contextually required relationship is and compare the two. What we believe the relationship to be is irrelevant.

The moral is not to conflate the reasonings, the mental processes, that go on inside our heads, with the arguments, the sets of statements, we advance..$^{20}$ I will grant that we may capture or express part of the reasoning from A to B when we write the argument 'A, thus B.' But it is only a part and we do not want to conflate the two or think that because there are deductive and inductive reasonings there must be deductive and inductive arguments. Reasonings can be usefully distinguished on the basis of what the reasoner believes the relationship between premises and conclusion to be, but arguments cannot. At the same time, we can ground or explain the goodness or badness of particular deductive or inductive reasonings without appealing to corresponding deductive or inductive arguments. Instead we can hold that valid arguments with true premises will ground good deductive reasonings, and adequate but invalid arguments with true premises will ground good inductive reasonings, and that arguments which are either inadequate or have at 
least one false premise will explain why all other reasonings, whether deductive or inductive, are bad.

What of a distinction between deductive and inductive logic? Given my framework, one could say that deductive logic is the study of arguments (all arguments!) in terms of validity and invalidity. On the other hand, inductive logic is the study of arguments (all arguments!) in terms of adequacy (not including validity) and inadequacy. In other words, you are doing deductive logic if your adequacy standard is validity, and doing inductive logic if your adequacy standard is something less than validity.

To sum up: The mere fact that drawing a distinction between deductive and inductive arguments has been the actual practice of philosophers and logicians for over two thousand years does not establish that we really need to make such a distinction. At the same time, the pervasiveness of the making of a distinction can be explained by the fact that we can, if we wish, distinguish deductive reasoning from inductive reasoning or deductive logic from inductive logic without having to distinguish deductive arguments from inductive arguments. As long as we do not conflate reasoning processes with the arguments that may help justify them or try defining logics in terms of types of arguments, we can distinguish types of reasonings and logics in terms of validity and adequacy instead.

\section{Objection 2: Appropriateness}

David Hitchcock writes:

As several of my critics pointed out ..., in maintaining that there is more than one type of validity, I implicitly commit myself to criteria for determining which standard of validity is appropriate for a given argument. Thus, the distinction between deductive and inductive ... arguments reappears as the distinction between arguments for whose appraisal standards of deductive validity are appropriate and those for which inductive standards are appropriate. $^{21}$

Hitchcock ultimately accepts the objection and so someone might apply the same objection to my account, claiming that $\mathrm{I}$, too, presuppose a distinction between arguments for which validity is the appropriate standard and those for which some less stringent adequacy standard is appropriate.

Reply: Hitchcock is wrong to take the criticism seriously. The mere fact that my account has different degrees of adequacy does not entail that I need to classify arguments into those for which validity is the appropriate standard and those for which some lesser standard is appropriate. Firstly, there is no reason that one and the same argument cannot have more than one evaluative property just as one and the same student can meet a variety of evaluative standards. A student can have all A's, can have a 93.4\% average, can be on the Dean's List, etc. Similarly, an argument in virtue of the actual strength of the connection that holds between premises and conclusion might be both valid and adequate, or it might be invalid but adequate, or it might be both invalid and inadequate. 
Even advocates of the distinction talk as if arguments can have more than one evaluative property. For example, consider:

(3) A few patrons got sick. George was a patron, so George got sick.

(3) is a bad argument. Why? Because it is neither valid nor, speaking with the vulgar, inductively strong. Assuming all arguments are either valid or invalid or strong or weak, if the argument truly is neither valid nor inductively strong, then it is both invalid and inductively weak. But if arguments can be both invalid and weak, why not both valid and strong or, invalid but strong?

Secondly, the appropriate standard is independent of any given argumentwhat standard is appropriate depends upon the context in which the argument is given, and not on the argument itself. Reconsider argument (1)-All examined emeralds up to now are green, so the next emerald examined will be green. In the context of Descartes Meditations, which demands absolute certainty, this argument would be inadequate, but in other less stringent contexts it would be adequate. Since the argument is unchanged from context to context, and yet the standards of adequacy change, adequacy standards are independent of arguments. All that different adequacy standards presuppose is criteria for determining from the context which degree of adequacy is appropriate or required for the arguer's goals to be achieved. Nowhere do I presuppose that there are different kinds of arguments for each degree of adequacy.

\section{Objection 3: Oh that Inductive Feeling}

Robert Pargetter and John Bigelow, among others, note that inductive arguments have a 'distinctive aroma. ${ }^{\prime 22}$ Hence, one might point to the least intuitive way that we can quickly classify arguments into either deductive vs. inductive as an indicator that these types exist. There have to be two different sorts of arguments--the two sorts just feel (or smell) different!

Reply: What we can do quite quickly in many instances is recognize that an argument is valid. For example, consider:

(4) All people are mortal. Socrates is a person, so Socrates is mortal. or .

(5) George Sands is either a man or a woman. George is not a man, so George is a woman.

We can also recognize that any argument of the same form will be valid. Some of these forms we have given special names, such as categorical syllogism or disjunctive syllogism. At the same time we can also recognize other arguments that are not valid, but are often adequate (even if we cannot immediately produce a context in which it is adequate.) For example, consider:

(6) The sun has risen every day prior to and including today, so the sun will rise tomorrow.

or 
(7) Most glasses dropped from the top of hundred story buildings shatter. So, this glass will shatter if dropped from the top of a hundred story building.

Just as before, we recognize that these arguments have a form or structure that can be utilized (though perhaps not with the same generality that valid forms can be) to produce, in appropriate contexts, non-valid but adequate arguments.

Now one might say that we have revealed two classes of arguments: deductive and inductive respectively. One could say this, but then 'deductive' would just be another term for 'valid' and 'inductive' would be short for 'non-valid, but adequate' ${ }^{23} 1$ already recognize those classes of arguments. What does not follow, however, is that we are discovering a class of arguments to which it is appropriate to apply the standard of validity and a class to which it is appropriate to apply the standard of non-valid, but adequate. After all, we determined the class by recognizing that the arguments satisfy the standard and not the other way around. Also, the usual intent of saying that it is appropriate to apply a given standard is to say that given argument $\mathrm{A}$, it is appropriate to check whether $\mathrm{A}$ does or does not satisfy the standard. But in this case it is not appropriate. We already know that the argument satisfies the standard since that is how we classified the argument to begin with.

To summarize: We can account for the alleged distinctive 'flavor' or 'aroma' that arguments have in terms of 'validity' and 'non-valid, but adequate'. Hence, we do not have reason to distinguish inductive from deductive arguments.

\section{Objection 4: The History of Philosophy and the Philosophy of Science}

Historically, the distinction between deductive and inductive arguments is pervasive. Hence, to teach the history of philosophy accurately we need to make the distinction ourselves. For example, to teach Aristotle's, Locke's, or Hume's views on arguing will require making the distinction. And speaking of Hume, how can we teach Hume's problem of induction without appealing to the distinction? Even worse, the problem of induction has become one of the major problems of 20th century philosophy of science. Even more generally than just the problem of induction, many 20th century accounts of scientific explanation rest upon a distinction between inductive and deductive arguments. Hence, to teach the philosophy of science accurately we need to make the distinction ourselves.

Reply: Despite the broad scope of this objection, it has two main components, which I shall deal with in turn. Firstly, I admit that to teach the history of philosophy accurately we may need to say something like, 'Locke made a distinction between two sorts of arguments, deductive and inductive, and here is his distinction.' (I am not convinced this is what we would say to teach Locke accurately, but suppose it were). I will also admit that to teach some aspects of the philosophy of science correctly we may need to say something like, 'Carl Hempel attempts to distinguish two sorts of arguments, deductive and inductive, on the basis of which he posits two kinds of scientific explanation.' Does it follow from either of these 
facts that there are two sorts of arguments, deductive and inductive? No. For Locke and Hempel may have gotten things wrong and tried making a distinction that just wasn't there. Consider, for example, teaching Descartes's distinction between material and immaterial substances. Just because Descartes makes the distinction, are we thereby committed to two sorts of substances? No. For Descartes might have gotten things wrong. The mere fact that the distinction is pervasive does not imply that it is correct. After all, many times we present distinctions which are problematic precisely to demonstrate that they are problematic.

Secondly, Hume's 'problem of induction' can be stated and tentative solutions suggested without having to appeal to a distinction between deductive and inductive arguments. ${ }^{24}$ In a nutshell, the 'problem of induction' is merely the problem of justifying concluding something like 'the next emerald examined will be green' or 'all emeralds are green' from something like 'all emeralds observed up until now have been green.' If one demands valid arguments as the only grounds for justifying a reasoning process, then, as Hume points out, induction (the reasoning process) is unjustifiable, for to produce a valid argument we will need to add an additional premise such as 'the future will resemble the past in the relevant respects.' Unfortunately, our justification of that premise will rely on a claim such as 'the future has resembled the past in the relevant respects up until now.' But then our 'justification' of induction is circular for we are appealing to the very reasoning process we are trying to justify.

On the other hand, if one allows that invalid, but still adequate, arguments might ground a reasoning process, then solving the 'problem of induction' is merely showing that in some contexts in which achieving certainty is impossible, such as the context of scientific research and discovery, the observed evidence provides sufficient support for the conclusion in question. In other words, to show that an inductive reasoning process is justified is just to show that the degree of support the evidence conveys upon the conclusion is at least as great as the strength required by the context in which we advance the conclusion. Without doubt, actually demonstrating that the evidence sufficiently supports the conclusion may be an extremely difficult task, but that does not alter the fact that such a demonstration would solve the 'problem of induction.'

So, stating and discussing possible solutions to the problem of induction does not commit us to a distinction between deductive and inductive arguments. Instead the problem can be stated in terms of finding an argument to ground a certain sort of reasoning process. If only valid arguments will be accepted as the necessary ground, then there is evidence that inductive reasoning cannot be justified. If invalid but adequate arguments will be accepted, then we just need to show that there are such arguments. Hence, we need not be committed to a bona fide distinction between deductive and inductive arguments to teach or account for the problem of induction or to teach either the philosophy of science or the history of philosophy. 


\section{Objection 5: Implicit Premises}

James Freeman writes:

It is a commonplace that arguments are frequently stated incompletely. Indeed, supplying suppressed premises is a central topic in informal logic courses. When supplying a suppressed premise, there are two considerations to keep in mind. First, in a broad sense of logical including deductive and inductive concerns, the supplied premise must be logically needed if the argument is to be correct. ... To the extent that we can determine the intentions of the person putting forward the argument, our supplied premise must be in accord with those intentions. ${ }^{25}$

Freeman uses the following example:

(8) All Senators are politicians, so

All Senators are amoral.

of which he writes:

Adding either

(a) All politicians are amoral

or

(b) Most politicians are amoral

gives us a set of premises relevant to the conclusion. But I expect we all would regard the first as the correct premise to add, barring contextual evidence to the contrary. Why? ... We choose (a) because we recognize that ... $[(8)] \ldots$ is an incompletely stated categorical syllogism and so a deductive argument, and (a) produces a deductively correct argument. Hence, recognizing ... [(8)] ... as a deductive argument was a distinct factor in the process of identifying the proper suppressed premise to add ....

... Therefore, we see that judging whether arguments are deductive or inductive is a distinct step in the process of supplying suppressed premises. This is one reason for regarding the inductive/deductive distinction as applying to arguments. ${ }^{26}$

Reply: Without doubt, Freeman is correct to suppose that when adding suppressed premises we should, as much as possible, provide a premise that accords with the arguer's intentions. But does it follow that we need to judge whether an argument is deductive or inductive when supplying implicit premises? I think not. As Freeman himself admits, when the arguer's intentions are explicit they do not involve what kind of argument is being propounded, but rather a claim about the strength of the relationship between premises and conclusion. Such claims need not be interpreted as claims about type of argument, but rather as claims about what standards the argument satisfies. Hence, if someone provides the argument:

(9) All monkeys are primates, so with certainty all monkeys are mammals,

we need not recognize this as an incomplete categorical syllogism to know that the suppressed premise is probably 'all primates are mammals.' Instead we can recognize that the arguer, through the use of 'with certainty' means his argument to 
satisfy the standard of validity. The weakest premise that will satisfy validity is 'all primates are mammals.' Hence, we add that premise without ever needing to determine what kind of argument is being put forward.

Instead of attempting to determine the sort of argument the arguer intends in order to produce suppressed premises, I would advocate the following suppressed premise principle:

SPP: Where the arguer's intentions are explicit, add the weakest that will make the argument satisfy the standards the arguer intends his or her argument to satisfy. Where the arguer's intentions are not explicit add, if possible, the weakest premise that (i) is consistent with the arguer's other explicit views and (ii) makes the argument satisfy the standard required in the argument context.

But what if the arguer's intentions are made explicit by a claim such as 'all my arguments are deductive arguments'? Given that the deductive/inductive distinction has been long applied to arguments, we can expect people to express their intentions in terms of this unnecessary and quite possibly inadequate distinction. Regardless, we can still interpret their intentions as intentions about what standards they hope their arguments will satisfy, rather than taking them literally at their word. In other words, the claim that 'all my arguments are deductive' should be taken as indicating 'all my argument need to satisfy the standard of validity.' We can, therefore, respect arguer's intentions and still supply suppressed premises without ever appealing to a distinction between types of arguments.

\section{Conclusion}

So end the objections. Unless other, more cogent, reasons are forthcoming I see no reason to even attempt to divide arguments into deductive and inductive kinds. The work we wish to accomplish with arguments can be accomplished without appeal to this distinction. We can add suppressed premises, evaluate arguments, distinguish deductive from inductive reasoning, distinguish deductive from inductive logic, and teach the philosophy of science, the problem of induction, and the history of philosophy perfectly well without appealing to some mythical distinction between inductive and deductive arguments. For any argument the first question should not be- - is it deductive or inductive?', but rather should be- 'is it adequate?' Rescher is wrong - the distinction between deductive and inductive arguments is not one of the most important and fundamental ideas in logic - rather it is one of the most prevalent distractions in logic.

\section{Notes}

* Ancestors of this paper were read at the University of Richmond in April, 2000 and to the Virginia Philosophical Association in October, 2000. My thanks to both audiences for their comments, and especially to Michael Gettings, my commentator at the latter reading.

'Rescher (1964): 60. 


\section{G.C. Goddu}

${ }^{2}$ Copi and Cohen (1998): 28.

${ }^{3}$ Kelley (1998): 191-192.

${ }^{4}$ Freeman (1993): 218.

"Many of these versions fall into natural groups. Bowles (1994): 159-184, does an extensive analysis of many types of the deductive/inductive argument distinction. He rejects many and ultimately defends a version of his own.

${ }^{6}$ See, for example, Copi and Cohen, (1998): 7; Johnson (1992): 9.

${ }^{7}$ See, for example, Layman (1999): 1.

${ }^{8}$ See, for example, Bowles (1991): 1.

'See, for example, Bonevac (1999): 3; Bergmann, Moor, and Nelson (1998): 1; Hurley (1997): 1.

${ }^{10}$ See, for example, Tidman and Kahane (1999): 1; Hardegree (1994): 3.

"Descartes (1993): 14.

${ }^{12}$ If you object that the truth of the premises is too strong a requirement and that the premises merely need to be highly plausible or reasonable or whatever, then substitute whatever adequacy condition you want for the premises in the definition-it will have no bearing on the arguments of this paper.

${ }^{13}$ For some the indeterminacy is enough to argue that there is no inductive logic at all. See, for example, Bigelow and Pargetter (1998): 464-472; and Sellars, (1970): 83-103.

${ }^{14}$ Though, given (i) the ever increasing complexity of new proofs and (ii) the specialization of mathematicians to the point that very few are competent to determine the adequacy of a given proof, there have been some discussion of lowering the standard in mathematics lest progress in mathematics be halted.

${ }^{15}$ This assumes that determining whether the premises are true or whether the argument begs the question or is circular or is redundant does not depend upon making the distinction. Since no one who advocates making the distinction has argued that it is necessary for making these determinations, I shall continue to make the assumption.

${ }^{16}$ Fohr, (1980): 6.

${ }^{17}$ Govier, (1980): 8.

${ }^{18}$ Though of course many do since they define or explain deductive reasoning or logic in terms of deductive arguments.

${ }^{19}$ See for example, Pargetter and Bigelow(1997): 62-63.

${ }^{20}$ Mark Vorobej, for example, in his defense of a psychologically based definition of deductive arguments against other definitions does not distinguish reasonings from arguments and defines deductive arguments in a manner almost identical with how I define deductive reasonings. Regardless, while I agree with many of his arguments as applied to reasonings, whether his definition of deductive arguments is better than other such definitions is irrelevant to my current project of showing that we need not try to define a class of arguments as deductive at all. See Vorobej, (1992).

${ }^{21}$ Hitchcock, (1981): 15. See also Govier (1980): 3 and Fohr (1980): 7.

${ }^{22}$ Pargetter and Bigelow (1997): 65 .

${ }^{23}$ Bowles (1994) and Vorobej(1992), for example, both criticize equating 'deductive' with 'valid' and 'inductive' with 'non-valid, but adequate', on the grounds that a minimal adequacy condition on definitions of types of argument is that the definition allow for both adequate and inadequate arguments of each type.

${ }^{24}$ Given the extensive literature on the problem of induction and justifying induction a full defense of this claim would require more space than I can devote to it here.

${ }^{25}$ Freeman (1984): 39.

${ }^{26}$ Freeman (1984): 40. 


\section{References}

Bergmann, Merrie, James Moor and Jack Nelson. (1998). The Logic Book, $3^{\text {rd }}$ ed. New York: McGraw-Hill.

Bigelow, John and Robert Pargetter. (1998). "No Logic of Cogency: Reply to Oakley," Australasian Journal of Philosophy, 76: 464-472.

Bonevac, Daniel. (1999). Simple Logic. Fort Worth: Harcourt Brace.

Bowles, George. (1994). "The Deductive/Inductive Distinction," Informal Logic, 16: 159-184.

Bowles, George. (1991). "Evaluating Arguments: The Premise-Conclusion Relation," Informal Logic 13: 1-20.

Copi, Irving M. and Carl Cohen. (1998). Introduction to Logic, $10^{\text {th }}$ ed. Upper Saddle River: Prentice Hall.

Descartes, Rene. (1993). Meditations on First Philosophy. Donald A. Cress, trans., $3^{\text {rd }}$ ed. Indianapolis: Hackett Publishing Company.

Fohr, Samuel D. (1980). "Deductive-Inductive: Reply to Criticisms," Informal Logic Newsletter, iii. 1: 5-10.

Freeman, James B. (1984). "Reply to Englebretsen," Informal Logic Newsletter, vi. 3: 34 40.

Freeman, James B. (1993). Thinking Logically. Upper Saddle River: Prentice Hall.

Govier, Trudy (1980). "More on Deductive and Inductive Arguments," Informal Logic Newsletter ii.3: 7-8.

Hardegree, Gary. (1994). Symbolic Logic: A First Course. New York: McGraw-Hill.

Hitchcock, David. (1981). "Deduction, Induction, and Conduction," Informal Logic Newsletter, iii. 2: 7-15.

Hurley, Patrick J. (1997). A Concise Introduction to Logic, $6^{\text {th }}$ ed. Belmont: Wadsworth. Johnson, Robert M. (1992). A Logic Book, $2^{\text {nd }}$ ed. Belmont: Wadsworth.

Kelley, David. (1988). The Art of Reasoning, $3^{\text {rd }}$ ed. New York: W.W. Norton and Company.

Layman, C. Stephen. (1999). The Power of Logic. Mountain View: Mayfield Publishing Company.

Pargetter, Robert and John Bigelow. (1997). "The Validation of Induction," Australasian Journal of Philosophy, 75: 62-76.

Rescher, Nicholas. (1964). An Introduction to Logic. New York: St. Martin's Press.

Sellars, Wilfred. (1970). "Are There Non-Deductive Logics?" in Essays in Honor of Carl G. Hempel, N. Rescher et al., eds. Dordrecht: D. Reidel. pp. 83-103.

Tidman, Paul and Howard Kahane. (1999). Logic and Philosophy: A Modern Introduction, 8th ed. Belmont: Wadsworth.

Vorobej, Mark (1992), "Defining Deduction," Informal Logic 14: 105-118.

G.C. Goddu Department of Philosophy University of Richmond Virginia 23173 USA ggoddu@richmond.edu 